\title{
Maximising synergies between disaster risk reduction and climate change adaptation: potential enablers for improved planning outcomes
}

\author{
Authors: \\ Silvia Serrao-Neumann ${ }^{1}$; Florence Crick ${ }^{2}$; Ben Harman ${ }^{3}$; Gemma Schuch ${ }^{1}$; Darryl Low \\ Choy $^{1}$ \\ ${ }^{1}$ Urban Research Program, School of Environment, Griffith University, Australia \\ ${ }^{2}$ Grantham Research Institute, London School of Economics and Political Science, UK \\ ${ }^{3}$ CSIRO Land and Water Flagship, Dutton Park, Australia
}

\begin{abstract}
Recent extreme weather events worldwide have highlighted the vulnerability of many urban settlements to future climatic change. These events are expected to increase in frequency and intensity under climate change scenarios. Although the climatic change may be unavoidable, effective planning and response can reduce its impacts. Drawing on empirical data from a 3-year multi-sectoral study of climate change adaptation for human settlements in the South East Queensland region, Australia, this paper draws on multisectoral perspectives to propose enablers for maximising synergies between disaster risk reduction and climate change adaptation to achieve improved planning outcomes. Multisectoral perspectives are discussed under four groups of identified enablers: spatial planning; cross-sectoral planning; social/ community planning; and strategic/ long term planning. Based on the findings, a framework is proposed to guide planning systems to maximise synergies between the fields of disaster risk reduction and climate change adaptation to minimise the vulnerability of communities to extreme weather events in highly urbanised areas.
\end{abstract}

Key Words: adaptation planning, risk, pre-disaster planning, betterment, urban settlements, Australia

\section{Introduction}


Climate risks in urbanised areas are increasing with significant impacts on urban populations, economies and ecosystems, including extreme weather events leading to disasters (Revi and Satterthwaite, 2014; Wamsler, 2014). Urban planning and management (hereafter referred to as planning) plays a critical role in reducing climate risks through both spatial and strategic plan making and plan implementation (Berke and Campanella, 2006; Olshansky and Chang, 2009; Olshansky, 2006). Typically, planning policies have focused on minimising risks through prohibiting development in high risk areas and applying appropriate development controls (Harman et al., 2013; Wamsler, 2014). However, economic damages associated with disasters caused by extreme weather events have increased over time due to both social vulnerabilities and changes to physical hazards (Adger et al., 2005; Crompton and McAneney, 2008). As climate change is likely to escalate the frequency and intensity of extreme weather events (IPCC, 2014) increased pressure is being added to planning systems to implement more holistic measures to address future climate risks.

This paper argues that one lens through which planning can improve its ability to deal with forecast climate change impacts is by maximising synergies between strategies seeking disaster risk reduction and climate change adaptation. Arguments are based on empirical findings from the South East Queensland Climate Adaptation Research Initiative (SEQCARI), a three-year multi-sectoral study of climate change adaptation options for the South East Queensland (SEQ) region in Australia. Section 2 introduces the latest discussions on the interconnected fields of disaster risk reduction and climate change adaptation, followed by two key emerging concepts: betterment and post-disaster planning in the pre-disaster phase. Section 3 reports on the research approach and methodology along with a typology of enablers for maximizing synergies between disaster risk reduction and climate change adaptation based on multi-sectoral stakeholders' perspectives identified by the SEQCARI project. These enablers are described in section 4 and form the basis for the proposal of a framework for planning systems to reduce current and future vulnerability of highly urbanised areas to extreme weather events presented in section 5. 


\section{Conceptual underpinnings: (re) connecting disaster risk reduction and climate change adaptation}

There is an increasing understanding that climate change adaptation and disaster risk reduction are interconnected fields that deserve investigations seeking their overlaps and synergies (Birkmann and von Teichman, 2010; Gero et al., 2011; Howes et al., 2014; McBean and Ajibade, 2009; Schipper, 2009; Schipper and Pelling, 2006; Solecki et al., 2011). In the last decade there has been an increasing demand to integrate these two fields, especially within the international development arena, yet progress has been slow and examples of effective integration, especially at the national and local levels, remain limited (Birkmann and von Teichman, 2010; Gero et al, 2011; Mitchell et al, 2010). Despite calls for exploiting the synergies and identifying signs of convergence, there is very little guidance on how to integrate disaster risk reduction and climate change adaptation, as the relationship between both fields remains unclear. For example, Birkmann and von Teichman (2010) note how on the one hand it is argued that climate change adaptation needs to be mainstreamed into disaster risk reduction, while on the other disaster risk reduction is seen as a sector or cross-cutting theme within adaptation. In addition, both fields have different theoretical and cultural origins and are supported by different sets of institutions, methodologies and policy frameworks (Mitchell et al., 2010; Schipper, 2009; Tearfund, 2008).

Nevertheless, recent studies have identified some of the synergies as well as key challenges to the integration of these two fields (Birkmann and von Teichman, 2010; Mercer, 2010; Mitchell et al., 2010; Tearfund, 2008). Birkmann and von Teichman (2010) reviewed the literature and noted that the integration of the two fields is subject to challenges related to mismatch of temporal, spatial and functional scales as well as mismatches in norms and knowledge. These mismatches result in missed opportunities for integration and effective long term vulnerability reduction. For example, the recovery phase provides a window of opportunity for implementing long term disaster risk reduction measures yet this opportunity is often neglected and remains unused. In addition, the opportunity to rebuild in an adaptive way and to consider future climate 
change is in most cases not considered, as recovery tends to focus on building back as quickly as possible to pre-disaster conditions (Birkmann and von Teichman, 2010).

Integrating disaster risk reduction and climate change adaptation will demand 'greater collaboration between communities of policy makers, practitioners and researchers' (Howes et al., 2014:3). Additionally, Howes et al. (2014) suggest that integration could be interpreted as joined-up government efforts focused on elimitating policy trade-offs, improving use of resources and improving exchange of ideas and cooperation between stakeholders (Pollit, 2003 cited in Howes et al., 2014). In parallel, Wamsler (2014) argues that such integration can only occur, at least from a planning and theoretical perspective, if both fields are considered cross-cutting issues embedded in planning systems through a series of seven mainstreaming strategies. Such strategies should target three realms: (i) the implementation of specific programmes aimed at reducing climate and disaster risk; (ii) the modification of intra- and inter-organisational operational procedures such as management, policy and working structures to improve coordination in the implementation of programmes and reduce spill-over effects; and (iii) education and training of practitioners and policy makers on disaster risk reduction and climate change adaptation (Wamsler, 2009).

Despite the long history the disaster risk reduction community has in addressing hazards and vulnerability (Solecki et al., 2011), there is limited research available that can inform urban and regional planners to better address disaster risk reduction (Blanco et al., 2009a; Olshansky et al., 2012; Wamsler, 2014; Wamsler et al., 2013). In parallel, there is limited empirical analysis of effective climate change adaptation strategies that can be implemented through spatial and / or strategic planning (Hurlimann and March, 2012; Wamsler, 2014; Wamsler et al., 2013; Wise et al. 2014). Nevertheless, the core business of planning systems has to deal with a legacy of past decisions that potentially place many people as well as private and public assets at an increased risk of harm from current and future extreme weather events (Burby et al., 2000; Hurlimann and March, 2012; McDonald et al., 2010; Stevens et al., 2010a; Wamsler, 2014). For example, the impact of Hurricane Katrina on New Orleans is an exemplar of the vulnerability of communities 
falsely protected by hard infrastructure devices, such as coastal defence structures (Colten and Giancarlo, 2011; Heazle et al., 2013). Additionally, using the example of Melbourne's peri-urban area that was savaged by the 2009 Black Saturday fires, Buxton et al. (2011:11) highlight that despite the risks there has been continuous development in areas of 'increased and extreme bushfire threat from climate change'.

Nevertheless, planning responses aimed at better dealing with future climate change impacts could learn from past disaster recovery experiences, particularly from the windows of opportunity created in the post-disaster phase. In particular, Schipper (2009) argues that addressing risks before and after disasters occur comprises one of the synergies between climate change adaptation and disaster risk reduction. Recovering from the impacts of disasters involves multiple layers, including housing needs, restoration of infrastructure and facilities, restoration of economic activities as well as improved coping mechanisms of affected communities and individuals (Olshansky et al., 2012). While there is a trend toward immediate reconstruction and rebuilding of damaged structures to enable communities to recover more rapidly and return to pre-disaster normality (Kates et al., 2006; Schipper, 2009), rebuilding it back quicker can often lead to the amplification of the economic, social and environmental vulnerability of affected areas (Ingram et al., 2006).

Two emerging concepts could offer scope for the implementation of much needed robust planning measures seeking to better deal with impacts from current and future extreme weather events: betterment and post-disaster planning in the pre-disaster phase. In particular, changes facilitated by both concepts may include enabling long term recovery from disaster impacts and reducing the vulnerability of places and their communities to climate risks (Adger et al., 2009). Hence, taking urban and regional planning outcomes as the background context, there is potential to explore whether the synergies between disaster risk reduction and climate change adaptation could be maximised through both betterment and post-disaster planning in the pre-disaster phase (see Figure 1). 
The concept of betterment has emerged as an approach that questions the trend of rapid reconstruction and rebuilding of affected communities after being stricken by disasters (Kates et al., 2006). While reconstruction post-disaster is often seen as an opportunity to build better and more resilient structures, under a betterment approach reconstruction must also add 'value beyond what existed before the disaster' (Olshansky et al., 2006:357). Hence, under a betterment approach to reconstruction there are opportunities for considering future spatial and societal impacts caused by climate change. However,

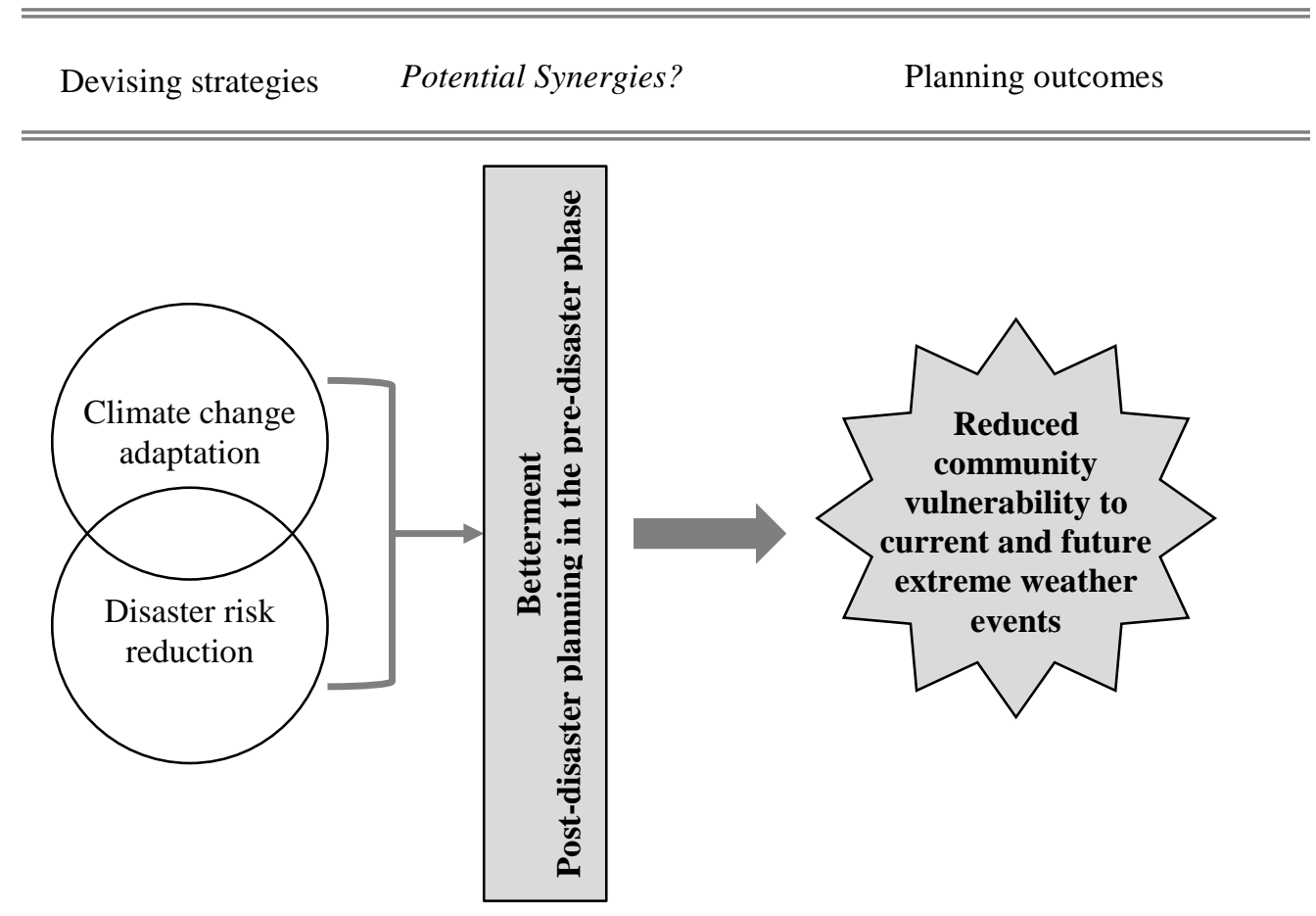

Research question: Are the concepts of betterment and post-disaster planning in the predisaster phase useful to maximise synergies between disaster risk reduction and climate change adaptation to achieve improved planning outcomes for urbanised areas?

\section{Figure 1. Conceptual underpinning}

reconstruction usually happens at a fast pace and conflicts arise between groups and institutions because different goals are not given sufficient attention in time, resources and values (Kates et al., 2006). Additionally, Kates et al. (2006) outline that the concept of betterment needs to be extended beyond physical structures, including improved urban planning practices, greater social equity and economic development focused on the strength of local industries. 
In parallel, the concept of post-disaster planning in the pre-disaster phase is also emerging as an alternative approach for disaster risk reduction that can be coupled to climate change adaptation. In essence, this approach calls for recovery planning to be proactive and abandon the traditional reactive mode (Meyer et al., 2010). It also 'recognises the importance of adjusting to new post-disaster realities' that are conducive to resilient states that aim at improved pre-disaster conditions (Manyena et al., 2011:420). In fact, successful long term recovery may well require planning for post-disaster recovery in the pre-disaster phase. Planning before a disaster occurs, whether it has slow or rapid onset, can ensure that communities and government agencies are sufficiently well prepared to negotiate the complexities and time compression challenges of postdisaster recovery (Florida State Emergency Response Team, 2011). However, successful post-disaster recovery can be highly constrained by a series of barriers. These include limited availability of funds, absence of pre-agreed planning policies for future development and existing planning institutions, and absence of planning processes involving well-established networks of community groups, lines of communication and planning tools (Olshansky et al., 2008).

\section{Research approach and methodology}

\subsection{The SEQCARI project}

Focusing on the South East Queensland region (SEQ), the Human Settlements component of the SEQCARI project took a case study approach (Flyvberg, 2006) to explore and develop a range of sectoral and cross-sectoral adaptation options for better governance and management in response to the impacts of climate change. Similar to other urbanised areas worldwide (Burby et al., 2000; Hurlimann and March, 2012; McBean and Ajibade, 2009; McDonald et al., 2010; Stevens et al., 2010a), SEQ is particularly vulnerable to climate change impacts due to rapidly growing population along its highly urbanised coastal areas and floodplains (Crick et al., 2012; Hennessy et al., 2007). In particular, the region has a legacy of past planning decisions attributed to traditional planning systems which often lacked holistic approaches and a focus on future 
conditions to implement land use strategies (McDonald et al., 2010; Oloruntoba, 2013). SEQ also has a history of being affected by extreme weather events such as the 2011 floods which resulted in the inundation of thousands of properties and significant damage to public infrastructure assets (The World Bank and Queensland Reconstruction Authority, 2011). Given its past and future climate related challenges, SEQ offers appropriate scope for exploring the synergies between strategies seeking disaster risk reduction and climate change adaptation.

SEQCARI was a 3-year multi-sectoral study involving the sectors of urban planning and management, coastal management, human health, emergency management and physical infrastructure at the local government scale. Data supporting this paper is based on 30 interviews carried out in 2011 with stakeholders from the five abovementioned sectors, including representatives from state government, local governments and non-government organisations (see Table 1). Interviews lasted an average of one hour and aimed to collect information related to existing and future climate change adaptation strategies across the region and sectors, including impacts and priorities, factors affecting policy development, barriers to effective action, opportunities for capacity building and integration of climate adaptation actions into other policy objectives. Data analysis involved in-depth content analysis (Bardin, 1977) followed by coding using NVivo software.

Table 1: Attributes of Stakeholder Interviews

\begin{tabular}{lcll}
\hline Stakeholder group & $\begin{array}{l}\text { Number of } \\
\text { Interviews }\end{array}$ & Predominant field of work & $\begin{array}{l}\text { Position in } \\
\text { organisation }\end{array}$ \\
\hline Local Government & 15 & $\begin{array}{l}\text { Planning, engineering, coastal } \\
\text { management, health, emergency } \\
\text { management }\end{array}$ & S, M, O\&M* \\
State Government & 7 & $\begin{array}{l}\text { Planning, engineering, coastal } \\
\text { management, health, emergency } \\
\text { management }\end{array}$ & E, S, M \\
Advisory Bodies & 3 & Planning, policy, capacity building & M \\
$\begin{array}{l}\text { Non-Government } \\
\text { Organisations (NGO) }\end{array}$ & 5 & $\begin{array}{l}\text { Planning, engineering, coastal } \\
\text { management, capacity building, }\end{array}$ & S, M \\
\hline
\end{tabular}

*E, executive; S, senior management; M, middle management; O\&M, operation and maintenance 
Based on the content analysis and the emerging concepts of betterment and post-disaster planning in the pre-disaster phase, a typology of enablers is proposed to maximise synergies between disaster risk reduction and climate change adaptation by planning systems. Figure 2 outlines this typology along with enablers that range from themes associated with spatial planning, cross-sectoral planning, social/ community planning and strategic/ long term planning. 


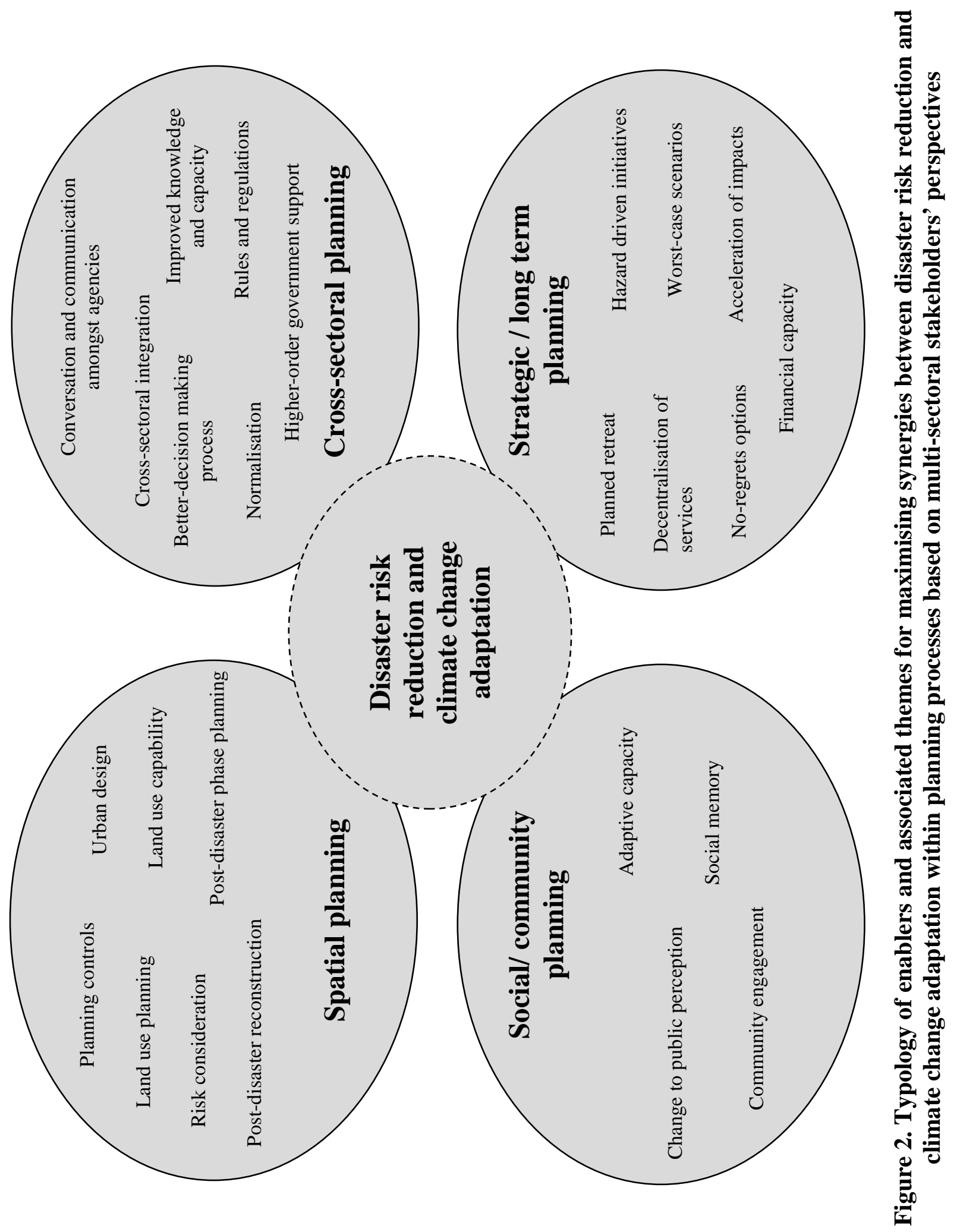




\section{Enablers for maximising synergies between disaster risk reduction and climate change adaptation}

\subsection{Spatial planning}

Many scholars have noted the role of spatial planning in disaster risk reduction (Berke et al., 2012; Olshansky et al., 2012) and climate change adaptation (Blanco et al., 2009b; Bulkeley et al., 2009). Analysis of multi-sectoral stakeholders' perspectives on climate change adaptation pointed to seven themes associated with spatial planning that could be translated into enablers to maximise synergies between disaster risk reduction and climate change adaptation as shown in Table 2. These themes ranged from typical planning functions such as land use planning, planning controls and urban design through to more complex tasks such as land use capability, risk consideration, post-disaster phase planning and post-disaster reconstruction.

Specifically, the role of land use planning, planning controls and urban design was especially linked to reducing the vulnerability of areas at risk. In this context, examples of potential enablers include urban consolidation through infill development in existing urbanised areas that have lower risks and therefore are less vulnerable to disasters, and improved building design standards that incorporate design criteria that allow structures to resist future loads potentially caused by climate change impacts during their service life. In terms of more complex spatial planning tasks, examples of enablers include formal recognition and extensive communication of climate risks affecting coastal areas through a full hazards disclosure law containing erosion rates, storm history, inundation and / or sea level rise. Enablers could also involve the strategic reallocation of health and emergency services departments into low risk areas and their upgrade to appropriate building standards to withstand future risks to secure their operation during emergencies. 


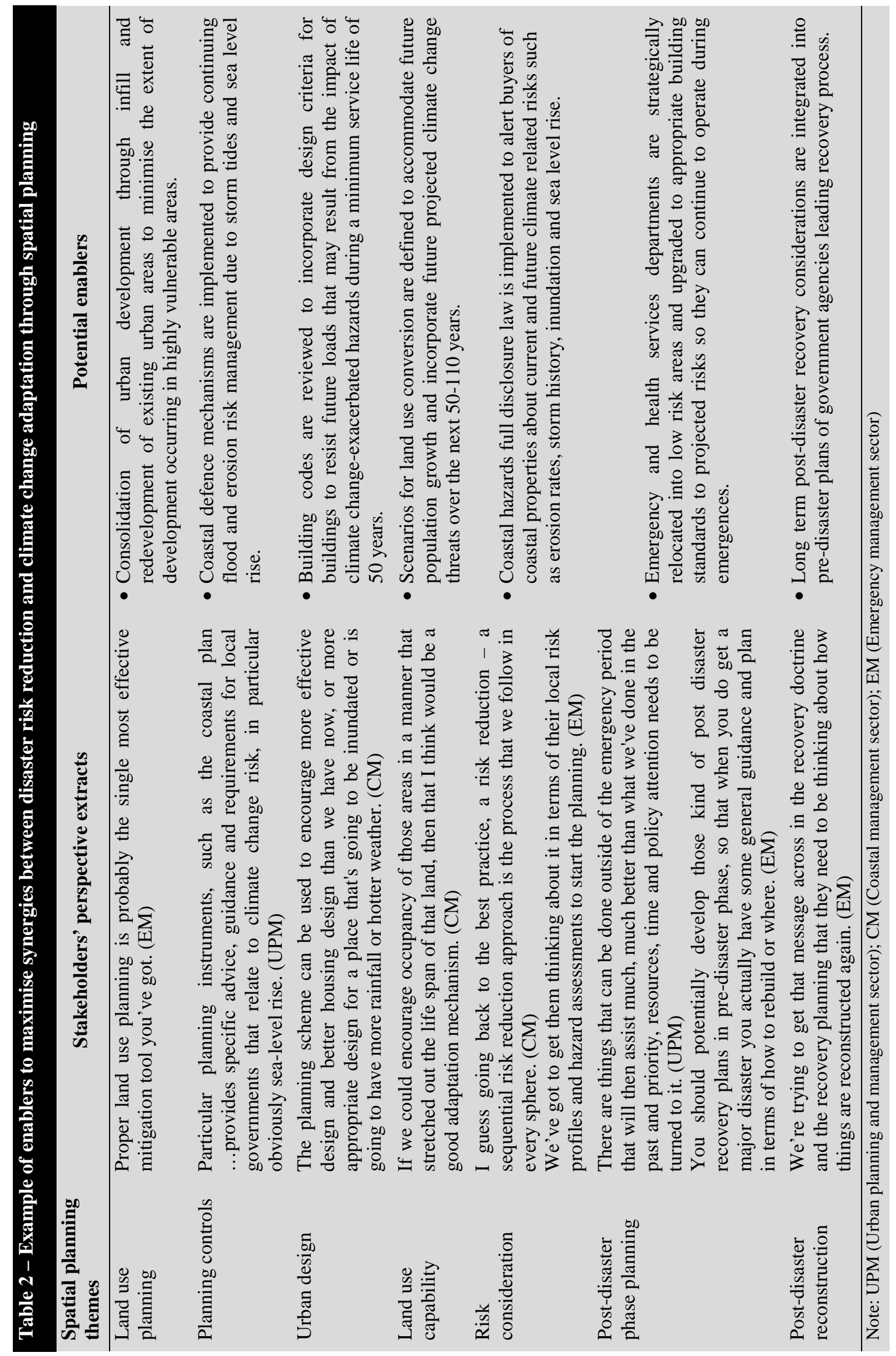




\subsection{Cross-sectoral planning}

Studies on climate change adaptation call for concerted actions by government, nongovernment, private and community sectors to enable the implementation and effectiveness of adaptation strategies (Birkmann and von Teichman, 2010; Low Choy et al., 2012; Taylor et al., 2013). Amongst these strategies are cross-sectoral adaptation options that result from improved integration of climate policy in decision-making processes to reduce policy trade-offs and subsequent maladaptation (Barnett and O'Neill, 2010; Serrao-Neumann et al., 2014a). The analysis of stakeholder interviews revealed seven themes associated with cross-sectoral planning as outlined in Table 3. Overall, themes relate to improved inter-agency collaboration, decision-making processes, regulatory frameworks and leadership.

Enablers for improved inter-agency collaboration and cross-sectoral policy implementation include the development of internal programs involving multiple agencies (such as emergency management, human health and planning agencies) to build capacity of state and local government practitioners for dealing with climate risks and associated impacts, as well as enhanced knowledge sharing across agencies. In particular, capacity building programs targeting practitioners from government agencies and other relevant organisations could involve risk management practices to facilitate the incorporation of risk allocation mechanisms into decision-making processes. 


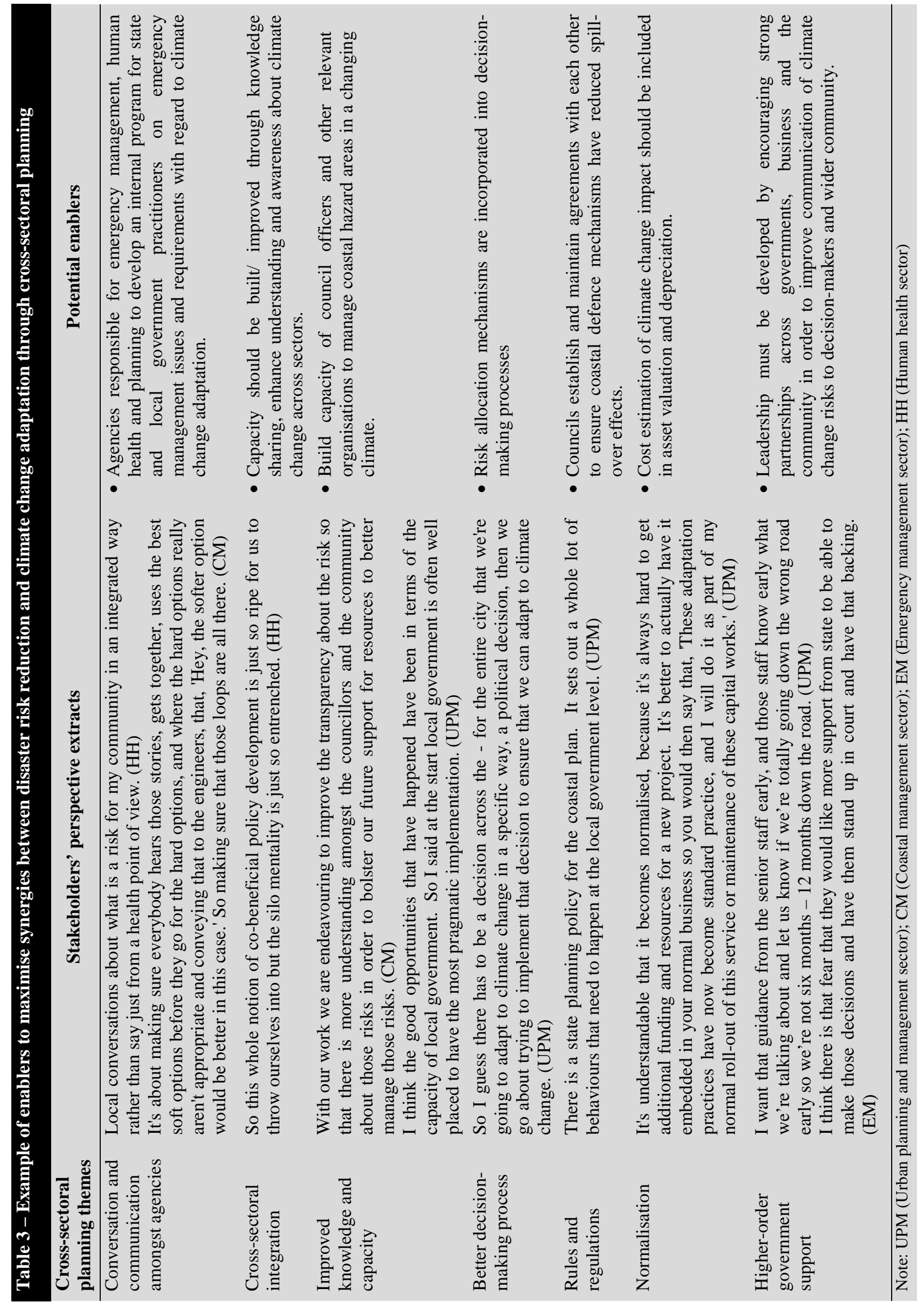


The effectiveness of regulatory frameworks seeking convergence of disaster risk reduction and climate change adaptation is dependent on the extent to which they cut across a range of government tiers and agencies. Specifically, effective cross-sectoral planning demands that rules and regulations are accompanied by inter-government agreements that ensure, for example, selected management options, such as coastal defence mechanisms, do not result in spill-over effects to other locations and therefore maladaptation. Additionally, disaster risk reduction and adaptation strategies need to be normalised in government businesses to ensure sufficient funding is allocated to deal with current and future risks. This type of normalisation is particularly important for infrastructure items which, in the Australian case, already face significant lack of funds for maintenance works without the extra burden expected to be added by more intense and frequent extreme weather events (Serrao-Neumann et al., 2011).

\subsection{Social/ community planning}

Individuals and communities play critical roles in disaster risk reduction. In particular, McBean and Rodgers (2010:878) note that educated individuals and communities that are aware of risks and vulnerabilities are able to produce strategies, such as 'pre-arranged collaborative actions', to both prepare for and recover from disasters. Additionally, these authors also highlight the importance of encouraging and enhancing changes in social and individual behaviour that are conducive to collective collaboration and cooperation, thereby improving their ability to respond to extreme weather events more effectively. Hence, social/ community planning offers an important compartment for enabling individuals and communities to better deal with current and future climate risks. Stakeholders identified themes related to social/ community planning that can be understood as enablers associated with capacity building, risk perception, disaster memory and community engagement (see Table 4). 


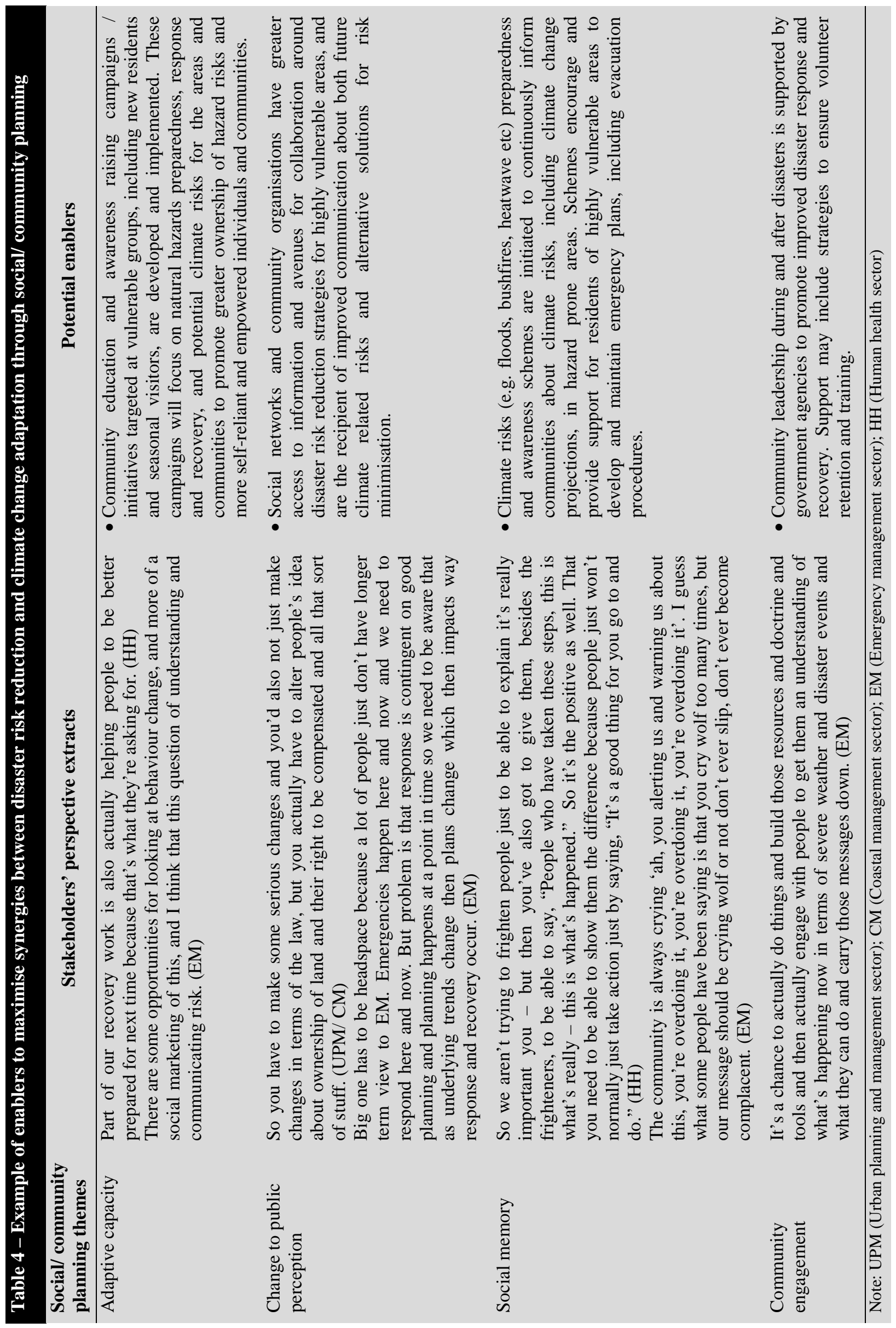


Amongst these enablers is the need for improving the adaptive capacity of individuals and communities that have been previously affected by natural hazards. In particular, community education and awareness raising campaigns could be implemented to harness people's willingness to be better prepared for future disasters and to ensure the recovery process is less traumatic. These campaigns, as outlined in Table 4, could focus on climate risks preparedness, response and recovery to promote greater community ownership of and responsibility to address risks.

Additionally, cultivating social memory related to previous extreme weather events could be seen as an enabler of proactive action towards adaptation and disaster risk reduction. A strategy to maintain social memory of extreme weather events involves preparedness and awareness schemes which continuously inform communities about climate risks and facilitate the development and adoption of emergency management plans. Lastly, enablers could also entail community engagement strategies targeting the preparation of community leaders and networks, including volunteers, that are supported by government agencies to take active roles in preparing for, responding to and recovering from disasters.

\subsection{Strategic / long term planning}

Adapting to climate change impacts and reducing disaster risks demand proactive action from government agencies to minimise the vulnerability of human settlements (Heazle et al., 2013; Quay, 2010; Serrao-Neumann et al., 2013b). As future changes and uncertainties are inherent to climate change impacts, strategic / long term planning aimed at minimising climate risks needs to deal with the variability and unpredictability of extreme weather events and their consequences. Multi-sectoral stakeholders pointed to seven different themes related to strategic/ long term planning that could be translated into enablers, including responses to climate risks, such as planned retreat, decentralisation of services and no-regrets options, through to acknowledgment of actual climate risks and financial needs (see Table 5). 


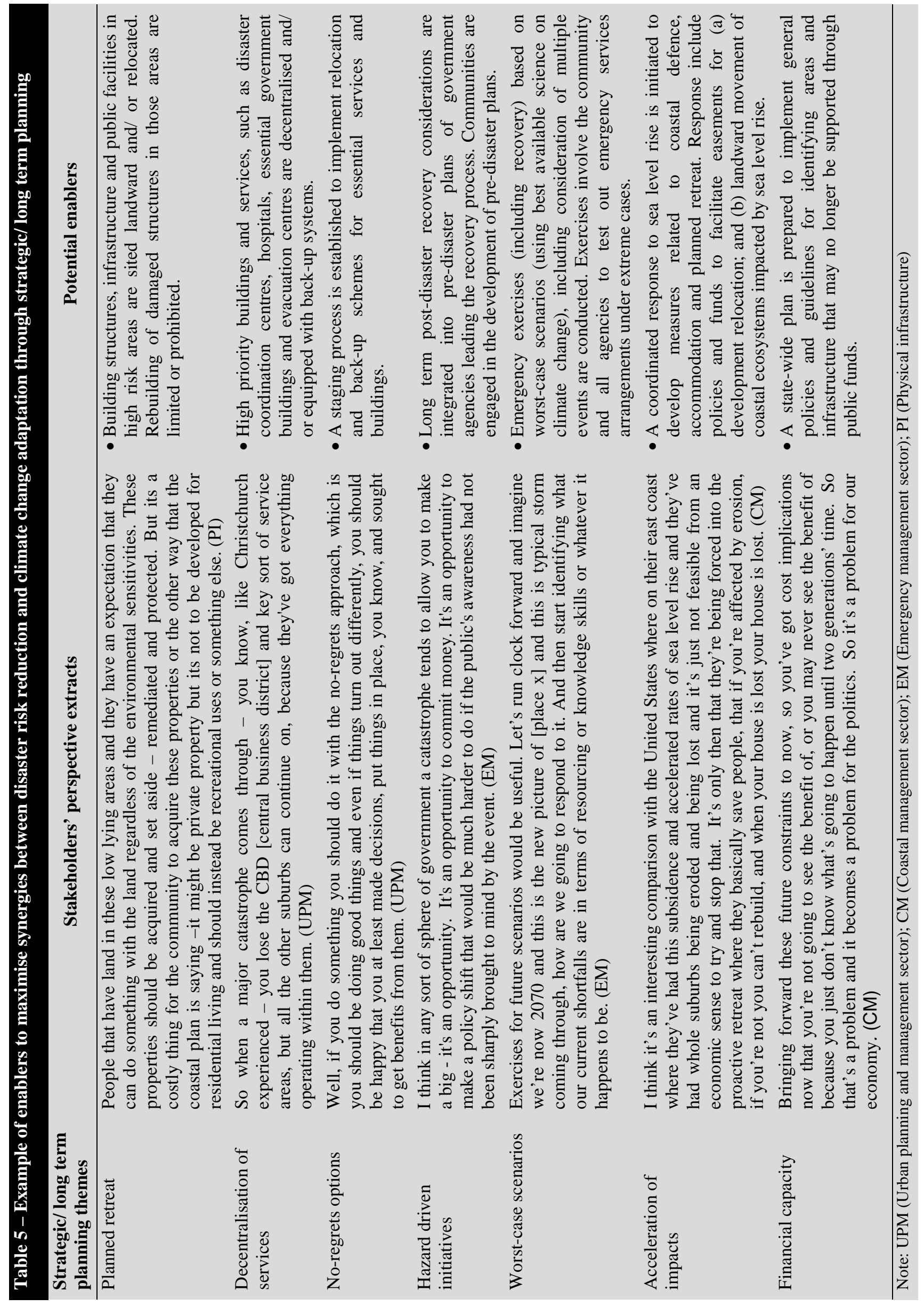


Enablers could be hazard-driven, focus on worst-case scenarios and assume the acceleration of impacts. For example, the reoccurrence of climate hazards offers opportunities for greater financial commitment to the emergency management sector and changing existing policies. Hence, enablers could involve the development of long term disaster recovery plans in partnership with affected communities. Additionally, the adoption of worst-case scenarios would be useful when running emergency exercises to test out emergency responses under extreme cases. In terms of acceleration of impacts, enablers include a coordinated response to climate risks affecting coastal areas, such as sea level rise, to determine the relocation of building structures and secure space for coastal ecosystems to shift landward.

\section{Moving forward: known constraints}

Maximising synergies between disaster risk reduction and climate change adaptation is critical to achieve improved planning outcomes in light of likely increases in the intensification and frequency of extreme weather events affecting highly urbanised areas. This section discusses how the emerging concepts of betterment and post-disaster planning in the pre-disaster phase could help maximise these synergies within planning processes by focusing on the four categories of enablers presented in section four: spatial planning, cross-sectoral planning, social/ community planning and strategic/ long term planning. In particular, based on a proposed framework (see Figure 2), the discussion highlights known constraints that need be considered by planning systems seeking to maximise these synergies through betterment and post-disaster planning in the predisaster phase. Constraints include considerations associated with: (i) compression in time and space for spatial planning; (ii) sectoral frictions for cross-sectoral planning; (iii) deficient engagement of communities for social/ community planning; and, (iv) reactive responses to climate risks for strategic/ long term planning.

\subsection{Compression in time and space}

Impacts from climate change are likely to be caused by known extreme weather events that can be exacerbated by the lack of preparedness of vulnerable human settlements. 


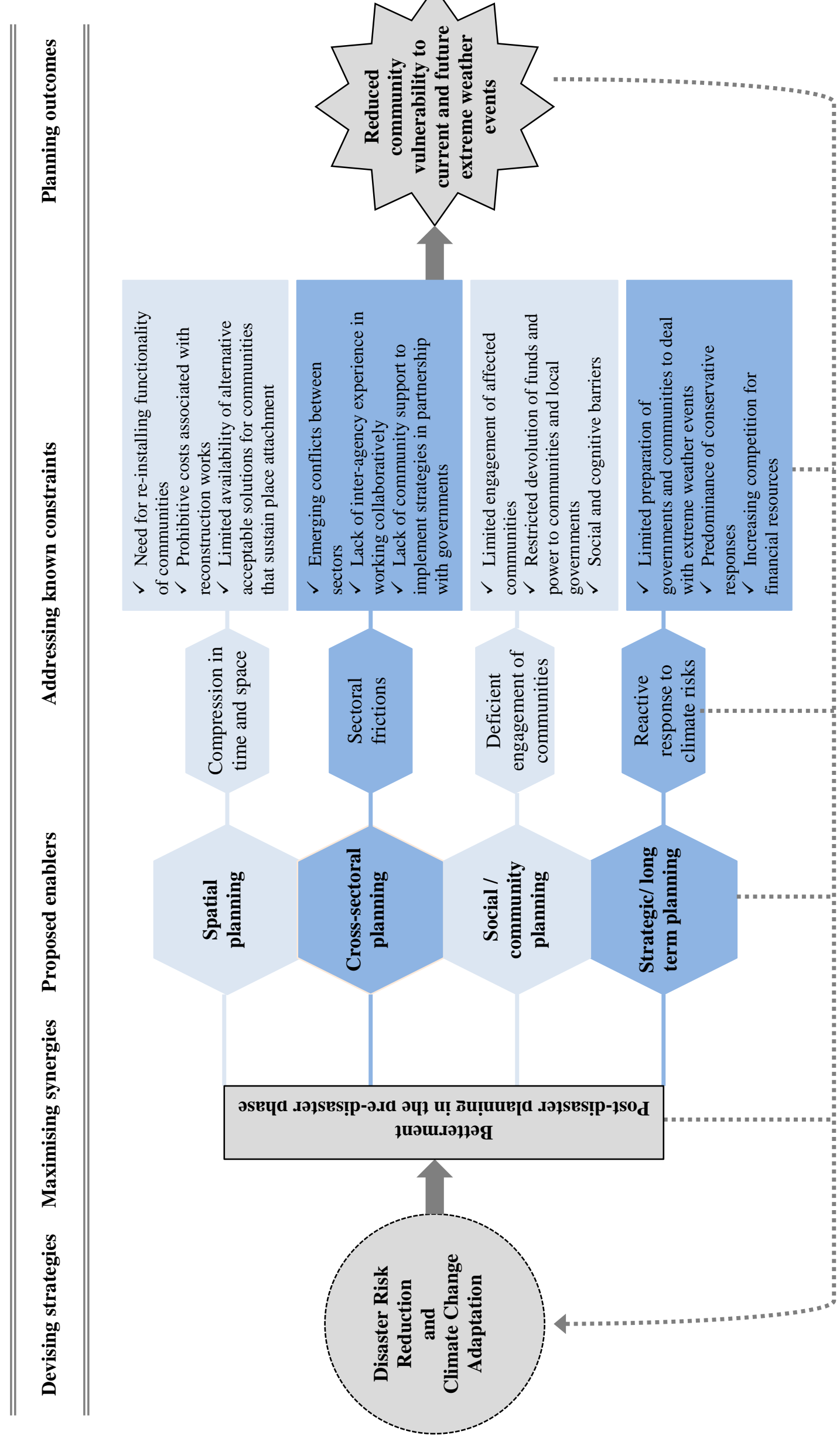

율 
Schipper (2009) argues that the primary goal of both disaster risk reduction and climate change adaptation has to focus on reducing the vulnerability of human settlements. Spatial planning strategies have a key role to play in facilitating and contributing to both disaster risk reduction and climate change adaptation, particularly by limiting the exposure of human settlements to increased risks (see Table 2).

Nonetheless, experiences from disaster stricken areas such as New Orleans highlight the challenges involved in advancing spatial planning strategies to incorporate trends put forward by emergent concepts of betterment and post-disaster planning in the pre-disaster phase, including improving the preparedness of human settlements to deal with future climate risks and reducing their exposure to such risks. For example, in post-disaster situations, Olshansky et al. (2012) stress that there is compression in time and space under which recovery activities such as reconstruction works need to occur. Such compression in time often impedes more robust solutions advocated by the betterment concept, such as rebuilding it back better, from being implemented due to a range of issues. These issues include, but are not limited to, re-installing the functionality of communities by repairing infrastructure, such as roads, as quickly as possible, and necessity of residents to return to affected places to re-connect with their family and friends and carry on with their lives. Unfortunately, once these functionalities are established it appears that opportunities to maximise improvements in disaster stricken areas to minimise future risks are not strongly pursued by planning authorities, thereby compromising betterment efforts. In particular, such efforts can be compromised due to both costs involved in improved reconstruction works and difficulty to offer residents alternative acceptable solutions that take into consideration their attachment to place.

On the other hand, the fact that the post-disaster phase requires sharp solutions due to compression in time and space to ensure communities return to function quickly presents the strongest argument for governments and communities alike to embrace post-disaster planning in the pre-disaster phase. For example, post-disaster planning in the pre-disaster phase offers communities the opportunity to improve their preparedness for future disasters by identifying priority areas, such as vulnerable neighbourhoods, that demand 
urgent programs to boost their adaptive capacity, and services, such as health and emergency facilities, that require upgrades and therefore greater allocation of funds. In addition, developing a post-disaster plan before a disaster occurs means that resources can be allocated and decision-making processes put in place to ensure that when a disaster strikes short term recovery priorities and political pressures do not outweigh and replace long term needs. Developing a clearly defined strategy for long term recovery before a disaster occurs enables communities to be proactive in their management of and response to disasters and avoid becoming victims to their circumstances (Meyer et al, 2010).

\subsection{Sectoral frictions}

The need for cross-sectoral planning in both disaster management and climate change adaptation has long been recognised and called for (Boullé et al., 1997; Buxton et al., 2011; Pearce, 2003; Siembieda et al., 2004; Yates and Bergin, 2009) and yet practical examples of effective operationalization of cross-sectoral planning on environmentrelated policy arenas remain scarce (Jordan and Lenschow, 2010). The lack of government agencies' experience in carrying out cross-sectoral planning involving disaster risk reduction and climate change adaptation can certainly compromise effective management of climate risks, especially when policies need to be formulated and implemented under inter-agency agreements (Amundsen et al., 2010; Dovers and Hezri, 2010). This lack of experience in inter-agency collaboration and cross-sectoral planning can also lead to the emergence of conflicts between sectors as those may compete for scarce funds and setting sector-specific policy agendas. Additionally, even when crosssectoral planning occurs at the policy formulation level, there is potential for delays in the policy implementation phase if appropriate mechanisms, such as legislation clarifying roles and responsibilities, are not in place to facilitate inter-agency collaboration. Hence, identified enablers for maximising synergies between betterment and post-disaster

planning in the pre-disaster phase approaches through cross-sectoral planning (see Table 3) need to take into consideration potential conflicts between sectors, and time-lag involved in implementing cross-sectoral strategies. 
Siembieda (2012) outlines that during the disaster recovery process agreements need to be reached by involved sectors to establish how recovery is to occur. For example, different tiers of governments may need to agree how the rebuilding of damaged infrastructures will take place and who will cover what costs. However, frictions between sectors due to conflict of interests can impede the achievement and implementation of such agreements. Simbieda (2012) emphasises two levels of frictions. On the one hand, frictions emerge across external sectors, particularly government tiers involved in the recovery/ reconstruction phase that only come together during this phase and do not have tradition in working collaboratively in the pre-disaster phase. On the other hand, frictions also emerge between what constitute the internal sector, including affected individuals and communities. In this case, existing community disputes can be exacerbated by disasters making it difficult for governments to take leadership and gain community support to implement more robust strategies (e.g. planned retreat) sought by betterment and post-disaster planning in the pre-disaster phase. Further, the author also highlights that the uncertainties between the two sectors greatly impede agreements to be reached in favour of improved actions/ strategies targeting risk reduction that would need to be implemented though partnerships between governments and the community.

Nevertheless, post-disaster planning in the pre-disaster phase and betterment approaches offer some hope for cross-sectoral planning seeking disaster risk reduction and climate change adaptation as it brings together sectors that have not traditionally worked together, including urban and regional planning, human health and emergency management. Additionally, if the community is also involved in post-disaster planning in the pre-disaster phase their needs are captured by the process and better understood by authorities. In this case, when agencies have a track record of collaboration and improved understanding of the needs of each sector, including the community, at times of disaster this experience can expedite inter-agency agreements which are legitimised by communities; thereby facilitating the recovery process and supporting strategies that have a long term perspective focused on reducing future vulnerabilities. 


\subsection{Deficient engagement of communities}

It is being increasingly recognised that communities should play an active role in improving their recovery and resilience to disasters (Norris et al., 2008). Accordingly, social / community planning offers important opportunities to bolster this active role if focused on building the community's capacity to deal with disaster risks (Zhang et al., 2013). Hence, greater community engagement and debate needs to occur to ensure strategies seeking both disaster risk reduction and climate change adaptation are not only socially acceptable but are also implemented in collaboration with communities (Hayward, 2013). However, a number of constraints need be acknowledged to maximise the potential of enablers related to social/ community planning (see table 4) for improving communities' capacity to deal with climate risks.

First, post-disaster circumstances also imply less time than normal for questions, decisions and actions to occur thereby limiting the engagement of affected communities in the decision-making process following disasters (Olshansky et al., 2012). Second, political barriers can impede the devolution of funds and power to communities and local

governments alike as reconstruction works involving large costs tend to be controlled by central governments and rolled out to specialised temporary agencies and portfolios to guide post-disaster recovery and reconstruction (Hayward, 2013; Lyons, 2009; SerraoNeumann et al., 2013a). Third, there are known social and cognitive barriers that can hamper efforts towards proactive adaptation (Lorenzoni et al., 2007; McBean and Ajibade, 2009). These include, but are not limited to, the 'lack of knowledge', 'uncertainty and scepticism', and 'distrust in information sources' as barriers at the individual level; and the 'lack of political action', 'social norms and expectations', and 'lack of enabling initiatives' at the social level (Lorenzoni et al., 2007: 450-1).

However, there are sufficient reasons to focus on social/ community planning through betterment and post-disaster planning in the pre-disaster phase as an enabler to maximise the synergies between disaster risk reduction and climate change adaptation. For example, Kates et al. (2006) argue that betterment approaches need to focus beyond 
physical structures to also include improvements in urban planning and social equity as well as economic opportunities that enhance and strengthen existing industries and therefore the community. Additionally, post-disaster planning in the pre-disaster phase is critical as increased reoccurrence of extreme weather events will challenge both communities' ability to respond appropriately to and effectively recover from disasters (Gunderson, 2010). In particular, extreme weather events leading to disasters can trigger a range of long term and intangible social costs. While the physical recovery can take a number of years, other impacts associated with economic stagnation, the disruption of social networks and the phasing out of post-disaster health care and support can last for decades (Olshansky and Chang, 2009).

Giegengack and Foster (2006) based on the post Hurricane Katrina impact on New Orleans, stress that risks from future hazards can be reduced in the short term but there is no 'technological fix' in the long term. These authors suggest that the vulnerability of places would be better dealt with through social measures instead of hard infrastructure solutions. In particular, social/ community planning in areas vulnerable to disaster risks should give specific attention to creating strategies that will facilitate both the reestablishment of social networks as well as community support prior and post disasters (Serrao-Neumann et al., 2013a). These could include strategies that target community strength and social inclusion such as facilitating the creation of partnerships amongst community sectors and groups through to improving skills development and promoting volunteerism.

Furthermore, hazard mitigation plans are only effective under significant public engagement, particularly in terms of increasing their quality as well as chances of being implemented (Stevens et al., 2010c). Thus, decision-making frameworks concerning disaster risk reduction and climate change adaptation through betterment and postdisaster planning in the pre-disaster phase need to embed sufficient flexibility for the inclusion of public engagement not only at the consultation end but also at implementation end of strategies (Hayward, 2013; Heazle et al., 2013; Serrao-Neumann et al., 2014b). In doing so, strategies are likely to have greater ownership by the involved 
communities as well as being socially acceptable. Such strategies need not only have a spatial planning nature to reduce and where possible mitigate climate change impacts but also take social aspects into consideration through improved social and/or community planning (Heazle et al., 2013; Serrao-Neumann et al., 2013b).

\subsection{Reactive response to climate risks}

While disaster management approaches have tended to focus more on reactive responses (Heazle et al., 2013) and on severe and sudden events rather than gradual and incremental changes (Davoudi et al., 2012), policy processes within disaster management need to address the future rather than respond well to the past (Handmer and Dovers, 2008). Additionally, one important aspect that needs to be accounted for in planning for disaster risk reduction and climate change adaptation is the 'notion that natural hazards are going to occur' (McBean and Rodgers, 2010:878). Hence, proactive action facilitated through strategic/ long term planning is needed to ensure governments and communities are better prepared to deal with the uncertainty of extreme weather events whether they are a consequence of climate change or not. In this context, strategic/ long term planning strategies seeking to maximise synergies between disaster risk reduction and climate change adaptation need to have a strong focus on the future, including how they are suited to address future vulnerabilities.

Nonetheless, identified enablers (see Table 5) for proactive action facilitated through strategic/ long term planning can be confronted by three key constraints: climate and institutional uncertainty, conservative choices, and scarce funds. First, there is significant uncertainty in terms of timing and intensity of climate change impacts as well as the response that needs to be adopted by different tiers of governments and communities to deal with such impacts (Dovers and Hezri, 2010). In fact, uncertainty related to climate science has been an impediment to proactive action in the planning sector (Camacho, 2009; Quay, 2010; Serrao-Neumann et al., 2013b). Uncertainty also challenges disaster risk reduction strategies as they may require some degree of flexibility that enables them to deal with the changing profile of risks under climate change to effectively enhance resilience and reduce vulnerability (Solecki et al., 2011). However, typically, flexibility 
in decision-making has not been a trend in the planning sector (Quay, 2010). In fact, planning has been dominated by a 'command and control' approach to land use planning focused on 'certainties' that also played its part in providing people with a false sense of 'security' (Colten and Giancarlo, 2011; Manyena et al., 2011), acelerated development in areas at risk (Burby et al., 2006), and reduced opportunties for greater community engagement in decision-making (Hayward, 2013).

Second, despite the high level of uncertainty associated with climate change, thus far responses to forecast climate change impacts have been addressed through 'conservative' rather than more resilient choices (cf. Siembieda, 2012). Strongly associated with the command and control approach to land use planning, conservative choices are often supported by a combination of actions, including mitigation efforts, government interventions through financial support to mitigation works, and changes in building codes and disaster relief for individuals and businesses that promote development to continue to occur in areas at risk (Stevens et al., 2010b). Communities under uncertainty also prefer conservative choices that enable them to stay in the same location after disasters because they struggle to assess the value of relocating to unknown/ unfamiliar locations (Siembieda, 2012).

Third, barriers to proactive planning responses also include limited financial resources allocated to climate change adaptation (Wise et al., 2014). However, as more people inhabit risk areas, the financial costs associated with protecting them from current and future impacts being it sea level rise, floods or storm surges are likely to rise as the magnitude and consequences of disasters are directly related to people's and places' vulnerability (Wamsler, 2014). Additionally, as extreme weather events become more frequent and intense governments' financial capacity will be further stretched to effectively recover from and rebuild after disasters. Consequently, a larger percentage of costs associated with recovery may shift to citizens (Kwadijk et al., 2010). For example, Berke et al. (2009) note that citizens in countries such as the USA are already bearing the full spectrum of losses in disasters whilst governments are failing to be proactive in protecting their citizens. 
Given this set of constraints to proactive responses facilitated through strategic/ long term planning, there are greater reasons for planning systems to adopt the approaches of betterment and post-disaster planning in the pre-disaster phase to maximise synergies between disaster risk reduction and climate change adaptation. In particular, to overturn the increased development of areas at risk, there have been calls for policies that mandate governments to prepare comprehensive plans that take climate risks into consideration, and to bear greater financial responsibility for the consequences of decision-making facilitating such development to occur (Berke et al., 2009; Burby, 2006). Such plans could be prepared through post-disaster planning in the pre-disaster phase. Additionally, while financial limitations to support disaster risk reduction and climate change adaptation are likely to continue in the future given the competition for more scarce resources, strategic / long term planning should aim for strategies that are strongly directed to building resilience and adaptive capacity of governments and communities, and setting priorities for action (Heazle et al., 2013). Further, disaster risk reduction literature points to windows of opportunities that emerge after disasters as catalysts for 'social transformation', including governance regimes (Pelling, 2010; Pelling and Manuel-Navarrete, 2011) and transforming barriers into enablers (Burch, 2010). For example, the financial constraint associated with the increase in the occurrence and frequency of extreme weather events may function as a catalyst for the prioritisation of adaptation and disaster risk reduction strategies as well as greater investment in building capacity and resilience of communities and governments.

\section{Conclusion}

Reducing communities' vulnerability to extreme weather events comprises a critical challenge for planning systems in light of likely increases in intensity and magnitude of climate change impacts to affected urbanised areas. Despite calls for better integration between disaster risk reduction and climate change adaptation, to date, there have been limited examples of successful integration. This paper has highlighted that there are advantages in maximising synergies between the fields of disaster risk reduction and 
climate change adaptation within planning processes to achieve improved planning outcomes in at-risk areas. The paper suggested that synergies between the two fields could be maximised through the emergent concepts of betterment and post-disaster planning in the pre-disaster phase, and identified four categories of potential enablers within planning processes: spatial planning, cross-sectoral planning, social/ community planning and strategic/ long term planning. Findings indicated that although there are promising opportunities offered by the concepts of betterment and post-disaster planning in the pre-disaster phase, attention should be paid to known constraints to their full operationalization.

For example, while betterment is not a new concept, its main focus has tended to be on physical infrastructure and it has not been fully applied in terms of the social dimension. Additionally, with the exception of few examples from the State of Florida, the concept of post-disaster planning in the pre-disaster phase is very recent and it is yet to be applied in other contexts or settings. This does suggest that there are many barriers that may need to be overcome in order to apply such approaches. However, with the increasing risks due to climate change it is now time for these two concepts to become more mainstream and be considered more fully by governments as a key way of maximising the synergies between disaster risk reduction and climate change adaptation and therefore helping to reduce long term vulnerability of communities to extreme weather events. Although this will not be a straightforward process, there are four key principles that can be drawn based on findings and discussion to guide future efforts within planning processes: (i) informed and confident political, private sector and community leadership; (ii) informed, engaged and prepared community; (iii) continuity of effort; and (iv) integrated and coordinated action.

First, a strong, positive and committed leadership at all levels in government, the private sector and the community is required to improve the communication about climate risks as well as establishing planning and decisions horizons that focus on addressing future vulnerabilities. These attributes of strong leadership should be informed through full community engagement processes and seek community partnerships for action. 
Leadership of this nature requires the support of awareness, training, education and capacity building programs.

Second, an informed, engaged and prepared community, inclusive of all citizens, that compliments strong leadership to jointly and successfully implement strategies to achieve the overarching goal of disaster risk reduction and climate change adaptation is critical. A high level of community engagement should be positioned in a bottom-up approach that facilitates a highly consultative partnership supporting, rather than being replaced by, strong leadership. This requires a community with high adaptive capacity capable of managing the climate risk especially during the response and recovery phases and seizing opportunities that arise as a consequence of disasters. Informed and prepared communities need the support of awareness, training, education and capacity building programs.

Third, initiatives supporting successful long term disaster risk reduction and climate change adaptation, such as awareness, training, education and capacity building programs, need to be adequately resourced to maintain continuity of effort and message. The continuity and longevity of initiatives, especially awareness and capacity building programs and campaigns, need to be of high quality, cost effective, targeted to specific groups and audiences, inclusive of vulnerable groups and presented in non alarmist terms to avoid negative messaging.

Last, high degrees of collaboration will only be achieved if there is effective integration and coordination of actions that address horizontal and vertical linkages across a region or system. This calls for a 'whole of government' approach to the development and implementation of policies, programs and actions, which typically fall across a number of separate sectors. Efficient interoperability between agencies at all levels will be a key ingredient to achieving this intent. 


\section{Acknowledgement}

This paper is part of the South East Queensland Climate Adaptation Research Initiative, a partnership between the Queensland and Australian Governments, the CSIRO Climate Adaptation National Research Flagship, Griffith University, The University of the Sunshine Coast and The University of Queensland. The Initiative aims to provide research knowledge to enable the region to adapt and prepare for the impacts of climate change.

\section{References}

Adger, N., Hughes, T., Folke, C., Carpenter, S., Rockström, J., 2005. Social-ecological Resilience to Coastal Disasters. Science 309, 1036-1039.

Adger, W., Dessai, S., Goulden, M., Hulme, M., Lorenzoni, I., Nelson, D., Naess, L., Wolf, J., Wreford, A., 2009. Are there social limits to adaptation to climate change? Climatic Change 93, 335-354.

Amundsen, H., Berglund, F., Westkog, H., 2010. Overcoming barriers to climate change adaptation - a question of multilevel governance? Environment and Planning C: Government and Policy 28, 276 - 289.

Bardin, L., 1977. Análise de conteúdo. Edições 70, Lisboa.

Barnett, J., O'Neill, 2010. Maladaptation. Global Environmental Change 20, 211-213.

Berke, P., Smith, G., Lyles, W., 2012. Planning for Resiliency: Evaluation of State Hazard Mitigation Plans under the Disaster Mitigation Act. Natural Hazards Review 13, 139-149.

Berke, P.R., Campanella, T.J., 2006. Planning for Postdisaster Resiliency. The ANNALS of the American Academy of Political and Social Science 604, 192-207.

Berke, P.R., Yan Song, Stevens, M., 2009. Integrating Hazard Mitigation into New Urban and Conventional Developments. Journal of Planning Education and Research 28, 441-455.

Birkmann, J., von Teichman, K., 2010. Integrating disaster risk reduction and climate change adaptation: key challenges-scales, knowledge, and norms. Sustainability Science 5, 171-184.

Blanco, H., Alberti, M., Forsyth, A., Krizek, K., Rodriguez, D., Talen, E., Ellis, C., 2009a. Hot, congested, crowded and diverse: Emerging research agendas in planning. Progress in Planning 71, 153-205. 
Blanco, H., Alberti, M., Olshansky, R., Chang, S., Wheeler, S.M., Randolph, J., London, J.B., Hollander, J.B., Pallagst, K.M., Schwarz, T., Popper, F.J., Parnell, S., Pieterse, E., Watson, V., 2009b. Shaken, shrinking, hot, impoverished and informal: Emerging research agendas in planning. Progress in Planning 72, 195-250.

Boullé, P., Vrolijks, L., Palm, E., 1997. Vulnerability reduction for sustainable urban development. Journal of Contingencies and Crisis Management 5, 179-188.

Bulkeley, H., Schroeder, H., Janda, K., Zhao, J., Armstrong, A., Chu, S., Ghosh, S., 2009. Cities and Climate Change: The role of institutions, governance and urban planning, Report prepared for the World Bank Urban Symposium on Climate Change.

Burby, R., Deyle, R., Godschalk, D., Olshansky, R., 2000. Creating Hazard Resilient Communities through Land-Use Planning. Natural Hazards Review 1, 99-106.

Burby, R., Nelson, A., Sanchez, W., 2006. The problems of containment and the promise of planning, In: Birch, E., Wachter, S. (Eds.), Rebuilding Urban Places after Disaster: Lessons from Hurricane Katrina. University of Pennsylvania Press, Philadelphia, pp. 4765.

Burby, R.J., 2006. Hurricane Katrina and the Paradoxes of Government Disaster Policy: Bringing About Wise Governmental Decisions for Hazardous Areas. The ANNALS of the American Academy of Political and Social Science 604, 171-191.

Burch, S., 2010. Transforming barriers into enablers of action on climate change: Insights from three municipal case studies in British Columbia, Canada. Global Environmental Change 20, 287-297.

Buxton, M., Haynes, R., Mercer, D., Butt, A., 2011. Vulnerability to Bushfire Risk at Melbourne's Urban Fringe: The Failure of Regulatory Land Use Planning. Geographical Research 49, 1-12.

Camacho, A., 2009. Adapting governance to climate change: managing uncertainty. Emory Law Journal 59, 1-70.

Colten, C.E., Giancarlo, A., 2011. Losing Resilience on the Gulf Coast: Hurricanes and Social Memory. Environment: Science and Policy for Sustainable Development 53, 6-19.

Crick, F., Serrao-Neumann, S., Low Choy, D., Sano, M., Baum, S., 2012. A Region at Risk: Policy Determination Through Vulnerability Hotspot Assessment, Resilient Cities 2. Cities and adaptation to climate change - Proceedings of the Global Forum 2011. Springer, Dordrecht Heidelber New York London

Crompton, R.P., McAneney, K.J., 2008. Normalised Australian insured losses from meteorological hazards: 1967-2006. Environmental Science \& Policy 11, 371-378.

Davoudi, S., Shaw, K., Haider, L.J., Quinlan, A.E., Peterson, G.D., Wilkinson, C., Fünfgeld, H., McEvoy, D., Porter, L., Davoudi, S., 2012. Resilience: A Bridging Concept 
or a Dead End? "Reframing” Resilience: Challenges for Planning Theory and Practice Interacting Traps: Resilience Assessment of a Pasture Management System in Northern Afghanistan Urban Resilience: What Does it Mean in Planning Practice? Resilience as a Useful Concept for Climate Change Adaptation? The Politics of Resilience for Planning: A Cautionary Note. Planning Theory \& Practice 13, 299-333.

Dovers, S.R., Hezri, A.A., 2010. Institutions and policy processes: the means to the ends of adaptation. Wiley Interdisciplinary Reviews: Climate Change 1, 212-231.

Florida State Emergency Response Team, 2011. Post-Disaster Redevelopment Planning.

Flyvberg, B., 2006. Five misunderstandings about case-study research. Qualitative Inquiry 12, 219-245.

Gero, A., Méheux, K., Dominey-Howes, D., 2011. Integrating disaster risk reduction and climate change adaptation in the Pacific. Climate and Development 3, 310-327.

Giegengack, R., Foster, K., 2006. Physical Constraints on reconstructing New Orleans, In: Birch, E., Wachter, S. (Eds.), Rebuilding Urban Places after Disaster: Lessons from Hurricane Katrina. University of Pennsylvania Press, Philadelphia, pp. 13-33.

Gunderson, L., 2010. Ecological and Human Community Resilience in Response to Natural Disasters. Ecology and Society 15.

Handmer, J., Dovers, S., 2008. Policy development and design for fire and emergency management. The Australian Journal of Emergency Management 23, 21-29.

Harman, B.P., Heyenga, S., Taylor, B.M., Fletcher, C.S., 2013. Global Lessons for Adapting Coastal Communities to Protect against Storm Surge Inundation. Journal of Coastal Research.

Hayward, B.M., 2013. Rethinking Resilience: Reflections on the Earthquakes in Christchurch, New Zealand, 2010 and 2011. Ecology and Society 18, 6.

Heazle, M., Tangney, P., Burton, P., Howes, M., Grant-Smith, D., Reis, K., Bosomworth, K., 2013. Mainstreaming climate change adaptation: An incremental approach to disaster risk management in Australia. Environmental Science \& Policy 33, 162-170.

Hennessy, K., Fitzharris, B., Bates, B.C., Harvey, N., Howden, M., Hughes, L., Salinger, J., Warrick, R., 2007. Australia and New Zealand, In: Parry, M.L., Canziani, O.F., Palutikof, J.P., van der Linden, P.J., Hanson, C.E. (Eds.), Climate Change 2007: Impacts, Adaptation and Vulnerability. Contribution of Working Group II to the Fourth Assessment Report of the Intergovernmental Panel on Climate Change. Cambridge University Press, Cambridge, pp. 507-540.

Howes, M., Tangney, P., Reis, K., Grant-Smith, D., Heazle, M., Bosomworth, K., Burton, P., 2014. Towards networked governance: improving interagency communication 
and collaboration for disaster risk management and climate change adaptation in Australia. Journal of Environmental Planning and Management, 1-20.

Hurlimann, A.C., March, A.P., 2012. The role of spatial planning in adapting to climate change. Wiley Interdisciplinary Reviews: Climate Change 3, 477-488.

Ingram, J.C., Franco, G., Rio, C.R.-d., Khazai, B., 2006. Post-disaster recovery dilemmas: challenges in balancing short-term and long-term needs for vulnerability reduction. Environmental Science \& Policy 9, 607-613.

IPCC, 2014. Climate Change 2014: Impacts, Adaptation, and Vulnerability - Summary for Policymakers, Working Group II Contribution to the IPCC 5th Assessment Report Changes to the Underlying Scientific/Technical Assessment. IPCC, p. 44.

Jordan, A., Lenschow, A., 2010. Environmental policy integration: a state of the art review. Environmental Policy and Governance 20, 147-158.

Kates, R.W., Colten, C.E., Laska, S., Leatherman, S.P., 2006. Reconstruction of New Orleans after Hurricane Katrina: A research perspective. Proceedings of the National Academy of Sciences 103, 14653-14660.

Kwadijk, J.C.J., Haasnoot, M., Mulder, J.P.M., Hoogvliet, M.M.C., Jeuken, A.B.M., van der Krogt, R.A.A., van Oostrom, N.G.C., Schelfhout, H.A., van Velzen, E.H., van Waveren, H., de Wit, M.J.M., 2010. Using adaptation tipping points to prepare for climate change and sea level rise: a case study in the Netherlands. Wiley Interdisciplinary Reviews: Climate Change 1, 729-740.

Lorenzoni, I., Nicholson-Cole, S., Whitmarsh, L., 2007. Barriers perceived to engaging with climate change among the UK public and their policy implications. Global Environmental Change 17, 445-459.

Low Choy, D., Serrao-Neumann, S., Crick, F., Schuch, G., Sanò, M., van Staden, R., Sahin, O., Harman, B., Baum, S., 2012. Adaptation Options for Human Settlements in South East Queensland - Main Report,. Griffith University.

Lyons, M., 2009. Building back better: the large-scale impact of small-scale approaches to reconstruction. World Development 37, 385-398.

Manyena, S., O'Brien, G., O'Keefe, P., Rose, J., 2011. Disaster resilience: a bounce back or bounce forward ability? Local Environment 16, 417-424.

McBean, G., Ajibade, I., 2009. Climate change, related hazards and human settlements. Current Opinion in Environmental Sustainability 1, 179-186.

McBean, G., Rodgers, C., 2010. Climate hazards and disasters: the need for capacity building. Wiley Interdisciplinary Reviews: Climate Change 1, 871-884. 
McDonald, J., Baum, S., Crick, F., Czarnecki, J., Field, G., Low Choy, D., Mustelin, J., Sanò, M., Serrao-Neumann, S., 2010. Climate change adaptation in South East Queensland human settlements: Issues and context. unpublished report for the South East Queensland Climate Adaptation Research Initiative, Griffith University.

Mercer, J., 2010. Disaster risk reduction or climate change adaptation: Are we reinventing the wheel? Journal of International Development 22, 247-264.

Meyer, S., Henry, E., Wright, R., Palmer, C., 2010. Post-Disaster Redevelopment Planning: Local Capacity Building Through Pre-Event Planning. Journal of Disaster Research 5, 552- 564.

Mitchell, T., van Aalst, M., Silva Villanueva, P., 2010. Assessing progress on integrating disaster risk reduction and climate change adaptation in development processes, Strengthening Climate Resilience Discussion Paper 2. Institute of Development Studies.

Norris, F., Stevens, S., Pfefferbaum, B., Wyche, K., Pfefferbaum, R., 2008. Community Resilience as a Metaphor, Theory, Set of Capacities, and Strategy for Disaster Readiness. American Journal of Community Psychology 41, 127-150.

Oloruntoba, R., 2013. Plans never go according to plan: An empirical analysis of challenges to plans during the 2009 Victoria bushfires. Technological Forecasting and Social Change.

Olshansky, R., Chang, S., 2009. Planning for disaster recovery: emerging research needs and challenges. Progress in Planning 72.

Olshansky, R., Hopkins, L., Johnson, L., 2012. Disaster and Recovery: Processes Compressed in Time. Natural Hazards Review 13, 173-178.

Olshansky, R., Johnson, L., Topping, K., 2006. Rebuilding Communities Following Disaster: Lessons from Kobe and Los Angeles. Built Environment 32, 354-374.

Olshansky, R.B., 2006. Planning After Hurricane Katrina. Journal of the American Planning Association 72, 147-153.

Olshansky, R.B., Johnson, L.A., Horne, J., Nee, B., 2008. Planning for the Rebuilding of New Orleans. Journal of the American Planning Association 74, 273-287.

Pearce, L., 2003. Disaster Management and Community Planning, and Public Participation: How to Achieve Sustainable Hazard Mitigation. Natural Hazards 28, 211228.

Pelling, M., and K. Dill, K. , 2010. Disaster politics: tipping points for change in the adaptation of sociopolitical regimes. Progress in Human Geography 34, 21-37.

Pelling, M., Manuel-Navarrete, D., 2011. From resilience to transformation: the adaptive cycle in two Mexican urban centers. Ecology and Society 16, 11. 
Quay, R., 2010. Anticipatory Governance. Journal of the American Planning Association 76, 496-511.

Revi, A., Satterthwaite, D., 2014. Urban Areas, Climate Change 2014: Impacts, Adaptation, and Vulnerability. Working Group II Contribution to the IPCC 5th Assessment Report - Changes to the Underlying Scientific/Technical Assessment. IPCC.

Schipper, E.L., 2009. Meeting at the crossroads?: Exploring the linkages between climate change adaptation and disaster risk reduction. Climate and Development 1, 16-30.

Schipper, L., Pelling, M., 2006. Disaster risk, climate change and international development: scope for, and challenges to, integration. Disasters 30, 19-38.

Serrao-Neumann, S., Crick, F., Harman, B., Sano, M., Sahin, O., Staden, R., Schuch, G., Baum, S., Low Choy, D., 2014a. Improving cross-sectoral climate change adaptation for coastal settlements: insights from South East Queensland, Australia. Regional Environmental Change 14, 489-500.

Serrao-Neumann, S., Crick, F., Low Choy, D., 2013a. "You can kiss my Yasi” Recovering in time compression, State of Australian Cities Conference, Sydney.

Serrao-Neumann, S., Harman, B., Leitch, A., Low Choy, D., 2014b. Public engagement and climate adaptation: insights from three local governments in Australia. Journal of Environmental Planning and Management, 1-21.

Serrao-Neumann, S., Harman, B.P., Low Choy, D., 2013b. The Role of Anticipatory Governance in Local Climate Adaptation: Observations from Australia. Planning Practice \& Research 28, 440-463.

Serrao-Neumann, S., Low Choy, D., van Staden, R., Crick, F., Sahin, O., Guan, H., Chai, G., 2011. Climate Change Impacts On Road Infrastructure Systems And Services In South East Queensland: Implications for Infrastructure Planning and Management, State of Australian Cities Conference, Melbourne, 29 Nov-2 Dec, 2011.

Siembieda, W., 2012. Transactions and friction as concepts to guide disaster recovery policy. Int J Disaster Risk Sci 3, 38-44.

Siembieda, W., Baird, B., Topping, K., 2004. Actions towards disaster recovery - A global planning perspective. Focus 1.

Solecki, W., Leichenko, R., O’Brien, K., 2011. Climate change adaptation strategies and disaster risk reduction in cities: connections, contentions, and synergies. Current Opinion in Environmental Sustainability 3, 135-141.

Stevens, M., Berke, P., Song, Y., 2010a. Public Participation in Local Government Review of Development Proposals in Hazardous Locations: Does it Matter, and What Do Local Government Planners Have to Do with It? Environmental Management 45, 320335. 
Stevens, M., Song, Y., Berke, P., 2010b. New Urbanist developments in flood-prone areas: safe development, or safe development paradox? Natural Hazards 53, 605-629.

Stevens, M.R., Berke, P.R., Song, Y., 2010c. Creating disaster-resilient communities: Evaluating the promise and performance of new urbanism. Landscape and Urban Planning 94, 105-115.

Taylor, B.M., Harman, B.P., Inman, M., 2013. Scaling-Up, Scaling-Down, and ScalingOut: Local Planning Strategies for Sea-Level Rise in New South Wales, Australia. Geographical Research 51, 292-303.

Tearfund, 2008. Linking climate change adaptation and disaster risk reduction.

The World Bank, Queensland Reconstruction Authority, 2011. Queensland Recovery And Reconstruction In The Aftermath Of The 2010/2011 Flood Events And Cyclone Yasi, http://www.qldreconstruction.org.au/publications-guides/reports/world-bank-report

Wamsler, C., 2009. Operational framework for integrating risk reduction and climate change adaptation into urban development. Brookes World Poverty Institute (BWPI) \& Global Urban Research Centre (BARC), Manchester, UK.

Wamsler, C., 2014. Cities, Disaster Risk and Adaptation. Routledge, Taylor \& Francis, London and New York.

Wamsler, C., Brink, E., Rivera, C., 2013. Planning for climate change in urban areas: from theory to practice. Journal of Cleaner Production 50, 68-81.

Wise, R.M., Fazey, I., Stafford Smith, M., Park, S.E., Eakin, H.C., Archer Van Garderen, E.R.M., Campbell, B., 2014. Reconceptualising adaptation to climate change as part of pathways of change and response. Global Environmental Change.

Yates, A., Bergin, A., 2009. Hardening Australia - Climate change and national disaster resilience, Special Report. Australian Strategic Policy Institute.

Zhang, X., Yi, L., Zhao, D., 2013. Community-based disaster management: a review of progress in China. Natural Hazards 65, 2215-2239. 